\title{
Norwegian Childhood Diabetes Registry: Childhood onset diabetes in Norway 1973-2012
}

\author{
Torild Skrivarhaug \\ Norwegian Childhood Diabetes Registry, Department of Paediatric Medicine, Women and Children's Division, \\ Oslo University Hospital \\ Correspondence: Torild Skrivarhaug, Department of Paediatric Medicine, Oslo University Hospital, PB 4950, 0424 Oslo \\ E-mail: torild.skrivarhaug@medisin.uio.no Telephone: +47 22118765/23015648 Telefax: +47 22118663
}

\begin{abstract}
The Norwegian Childhood Diabetes Registry (NCDR) is a prospective, population-based, nationwide registry which systematically register all incident cases of childhood diabetes, and systematically monitors the outcome of diabetes care in children and adolescents. NCDR includes data on childhood onset diabetes since 1973, and diabetes care outcome since 2001. NCDR was founded with the following objectives: To improve the diagnostics, classifications and treatment of childhood-onset diabetes, surveillance of incidence of diabetes in children and adolescents, surveillance of quality of diabetes care in Norwegian paediatric departments, and to stimulate to research in diabetes.
\end{abstract}

\section{INTRODUCTION}

Diabetes mellitus with onset in childhood represents one of the most frequent chronic diseases in children and young adults. The incidence of childhood onset type 1 diabetes in Norway is the third highest in the world, next to Finland and Sweden (1). The incidence has been steadily increasing since 1973 until 2009 when a peak in incidence was observed; 36 per 100,000 year (2-4). In Norway, type 1 diabetes is the second most common chronic disease in children age 0-14 years and it represents more than $98 \%$ of all diabetes in children younger than 15 years. Yearly approximately 290-330 children are diagnosed with type 1 diabetes in Norway.

Type 1 diabetes is related to a significant burden to the patient and to the society because most cases require lifelong treatment with insulin as well as dayto-day monitoring and treatment of complications. The disease has an increased risk of late complications such as renal disease, blindness, amputations, heart disease and stroke. Despite advances in treatment, type 1 diabetes is still associated with considerable premature mortality, resulting from acute and chronic complications of diabetes (5-8), even in societies with unrestricted access to the treatment of diabetes and its complications.

Several studies provide clear evidence that better metabolic control, as measured by a lower HbAlc level, is associated with fewer and delayed microvascular and macrovascular complications (9-13). Followup data from the Diabetes Control and Complications Trial (DCCT) indicated that 5-7 years of poor glycemic control, even during adolescence and young adulthood, results in an increased risk of complications in the subsequent 6-10 years (14). HbAlc reflects level of glycemia over the preceding 4-12 weeks, weighted toward the most recent four weeks (15). HbA1c monitoring has been shown to be the most useful measure in evaluating metabolic control and is the only measure for which good data are available in terms of its relationship with later microvascular and macrovascular complications $(9,10)$.

\section{NORWEGIAN CHILDHOOD DiABETES REGISTRY}

\section{Establishment and collection of data}

Norwegian Childhood Diabetes Registry (NCDR) was established in 2006, and is financed by the SouthEastern Norway Regional Health Authority. The Women and Children's Division, Oslo University Hospital is responsible for the daily operation, data management and security. An informed consent is obtained from each patient and/or the parents, before the patient is registered. NCDR has a prospective registration of data; both incident cases and clinical data from yearly examinations of all children and adolescents with diabetes treated in paediatric departments in Norway. In addition, NCDR contains data from two earlier diabetes registries/research projects; The Norwegian Diabetes Registry and The Norwegian Childhood Diabetes and Quality project. After the merger to NCDR these two registries stopped existing as independent research registries/projects.

\section{Aims of the Norwegian Childhood Diabetes Registry}

NCDR was founded with the following objectives:

- Surveillance of incidence of diabetes in children and adolescents in Norway.

- To improve the diagnostics, classifications and treatment of childhood-onset diabetes.

- Surveillance of quality of diabetes care in Norwegian paediatric departments measured by $\mathrm{HbA} 1 \mathrm{c}$, acute complications, and implementation of screening procedures for late complications and associated diseases according to national and international guidelines for childhood diabetes (16). 
Incidence per 100,000 person years

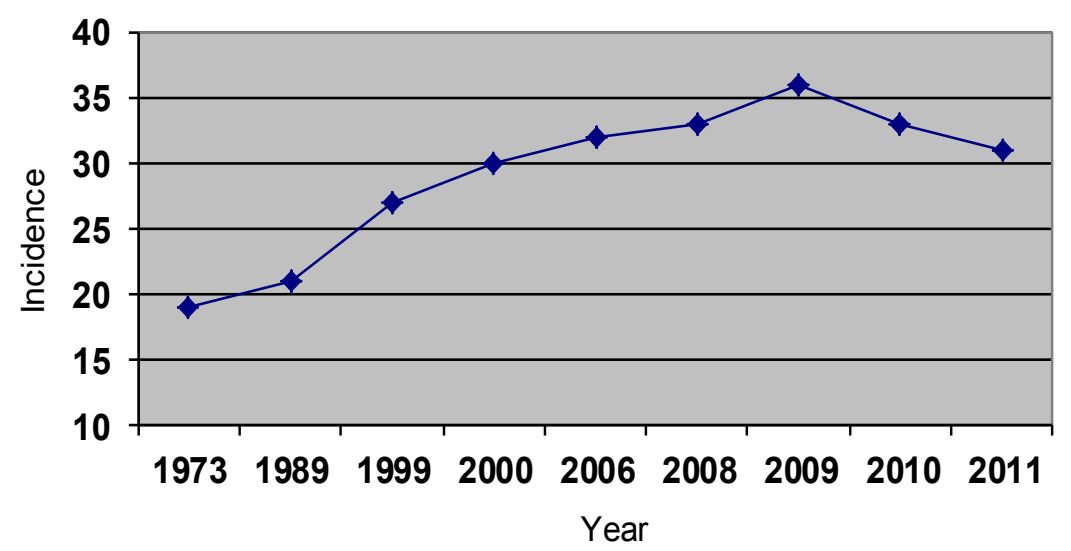

Figure 1. Incidence of Type 1 diabetes in children 0 -14 years in Norway, during 1973-2011. Norwegian Childhood Diabetes Registry.

- To ensure equal treatment to all children and adolescents with diabetes, and to stimulate to research in diabetes.

\section{The Norwegian Childhood Diabetes Study Group}

NCDR is based on the Norwegian Childhood Diabetes Study Group, a network of all paediatricians and diabetes nurses treating children and adolescents with diabetes in paediatric departments. Since 2008 all paediatric departments in Norway are reporting to NCDR.

\section{Main tasks}

The NCDR has four main tasks:

1) To collect standardized data from; i) incident cases, ii) yearly examinations (starting one year after diabetes onset).

2) To analyse and benchmark the data.

3) To report the data back to the paediatric departments and to the Health authorities.

4) To maintain and further develop the network for quality work among paediatric departments to ensure equal diabetes treatment throughout Norway.

\section{The Norwegian ChILdhood Diabetes REGISTRY ARE COLLECTING THE FOLLOWING DATA}

\section{New onset cases}

NCDR includes registration of all new onset cases of childhood diabetes. Data go back to 1973, collected retrospectively (2), and prospectively from 1989. From 2002 blood samples are collected together with clinical data in incident cases. Norway has since 1989 been one of the 23 EURODIAB centres reporting incidence of childhood onset type 1 diabetes in Europe (17). The completeness of ascertainment in NCDR is calculated to $91 \%(18)$.

\section{Annual data on diabetes care}

NCDR also includes prospectively collected, yearly, standardized clinical data on diabetes care, including
Table 1. Yearly registration of quality indicators in the Norwegian Childhood Diabetes Registry. Increasing numbers of paediatric clinics and numbers of participants, and increasing completeness in eligible patients 2001-2011.

\begin{tabular}{cccc}
\hline & $\begin{array}{c}\text { Number of } \\
\text { paediatric } \\
\text { clinics } \\
\text { (n) }\end{array}$ & $\begin{array}{c}\text { Number of } \\
\text { participants } \\
\text { (n) }\end{array}$ & $\begin{array}{c}\text { Completeness of } \\
\text { participants in } \\
\text { eligible patients } \\
(\%)\end{array}$ \\
\hline 2001 & 8 & 470 & - \\
2002 & 20 & 963 & - \\
2003 & 22 & 1129 & - \\
2004 & 23 & 1417 & 74 \\
2005 & 25 & 1664 & 75 \\
2006 & 25 & 1721 & 76 \\
2007 & 26 & 1836 & 82 \\
2008 & 26 & 2059 & 89 \\
2009 & 26 & 2341 & 93 \\
2010 & 27 & 2457 & 95 \\
2011 & 27 & 2567 & 95 \\
\hline
\end{tabular}

blood samples. Quality indicators are benchmarked. Sampling of data on diabetes care started with a few paediatric departments in 2001, including all the paediatric departments from 2008 (Table 1). Data are collected on a case record form based on the World Health Organization Basic Information Sheet for children and adolescents. HbAlc is determined for all participants by high-performance liquid chromatography (Tosoh G7; Tosoh Europe N.V., Belgium), at the same central DCCT-standardized laboratory (OUS, Aker).

The adherence rate on annual reporting has been rising from the start in 2001 until 95\% in 2010 and 2011. In 2011 all the paediatric departments participated with a total of 2567 patients; 98\% type 1 diabetes (2520/2567), 0.5\% type 2 diabetes (12/2567), $1.1 \%$ MODY (28/2567), $0.3 \%$ other types of diabetes $(8 / 2567)$.

\section{Quality indicators for diabetes care}

The Norwegian paediatric departments are anonymous benchmarked for the following quality indicators; 
HbA1c, severe hypoglycemia, hospitalization for diabetes ketoacidosis, completed screening of late complications (retinopathy, nephropathy, blood pressure, lipids), completed screening for associated diseases (celiac disease, hypothyroidism, hyperthyroidism). Screening for late complications and associated diseases is done according to ISPAD consensus guidelines (16).

\section{DATA FROM THE NORWEGIAN CHILDHOOD DIABETES REgISTRY}

Type 1 diabetes represents more than $98 \%$ of all diabetes registered in NCDR.

\section{1) Data at presentation of childhood onset type 1 diabetes}

\section{Incidence of childhood onset type 1 diabetes}

The incidence of type 1 diabetes diagnosed before 15 years has been increasing globally (1). The average increase per year has been 2.5-3.0 worldwide, however, wide variation in increase of type 1 diabetes has been well characterized by the DIAMOND project group (19) and from the EURODIAB study group $(17,20)$. The increase in incidence has not been uniform; several countries are showing periods of both less rapid and more rapid increase (17), and some reports a reverse trend (21). There is indication that the incidence is rising more steeply in some of the low prevalence countries $(1,20)$. Both Finland and Sweden have reported a decreasing incidence in recent years $(21,22)$.

Norway has had a steadily increasing incidence from 19.0 per 100,000 years in 1973 until 2009 when a peak in incidence was observed; 36 per 100,000 years (2-4). The increase in this period has however not been uniform; it includes both periods with more rapid increase and periods with no increase at all (2004-2008). After 2009 the incidence has declined, and in 2011 it was 31 per 100,000 years (23). The decrease has to be interpreted with caution, since it is still possible that this is a temporary phenomenon.

In childhood onset type 1 diabetes, the male-tofemale ratio has been reported to vary with the incidence level of the population under study. A slight excess of male patients was more often noted in high incidence countries $(22,24)$. Also in Norway there is a slight excess of boys. Several European studies have suggested that the increase in incidence of childhood onset type 1 diabetes, in relative terms, are greatest among children aged 0-4 years (25-28). This has never been the case in Norway, where the highest increase always has been in the age group 10-14 years.

It is indicated that the increasing incidence of childhood type 1 diabetes is not attributable to a global increase in disease incidence, but rather to earlier manifestation $(29,30)$. It is suggested that genetic susceptibility to develop type 1 diabetes has decreased over time due to an increasing environmental pressure and that this results in a higher disease progression rate in younger individuals. Norway has no complete registra- tion of incident cases with type 1 diabetes after the age of 15 years, and cannot contribute with data to this discussion.

\section{Diabetic ketoacidosis at presentation of childhood onset type 1 diabetes}

Diabetic ketoacidosis (DKA) is the leading cause of mortality in children with type 1 diabetes worldwide, and is associated with increased morbidity and healthcare expenditure. DKA is metabolic derangement characterised by the triad of hyperglycemia, acidosis and ketosis that occurs in the presence of very low levels of effective insulin action. The worldwide variation in incidence of type 1 diabetes in children has been well characterised, but there is less evidence concerning the frequency of DKA at diagnosis of type 1 diabetes. A study from Europe indicated that the frequency of DKA at diagnosis varied from $11 \%$ to $67 \%$ (31). The first published data from Norway on DKA at presentation of type 1 diabetes, reported that $18.0 \%$ of the children had DKA; $17.0 \%$ of the boys and $18.3 \%$ of the girls. Divided in age groups the proportions of patients with DKA were: age 0-4 years $16.3 \%$, age 5-9 years $11.3 \%$, age $10-14$ years $21.9 \%$. The severity of DKA is categorized by the degree of acidosis (16): $41 \%$ of the patients had mild DKA, $35 \%$ had moderate DKA and $23.5 \%$ had severe DKA (32).

\section{2) Annual data on diabetes care. The following data is from patients with type 1 diabetes}

\section{HbAlc}

The grand mean HbA1c of all clinics improved significantly $(\mathrm{p}<0.01)$ during the first 5 -yr period (20012005 ) from $8.6 \%$ to $8.2 \%$ (33). In 2011, the grand mean HbAlc was $8.3 \%$ (range 7.6-8.9). Before benchmarking the different paediatric departments, the mean $\mathrm{HbA1c}$ in each department is adjusted for gender, age and diabetes duration. In $2011,97 \%$ of the patients had a centrally analysed $\mathrm{HbA} 1 \mathrm{c}$.

\section{Severe hypoglycemia}

The term severe hypoglycemia is defined as episodes of hypoglycemia were the patient is semiconscious or unconscious with or without seizures (16). In 2011, severe hypoglycemia was reported in $6.3 \%$ of the patients, $1.3 \%$ had more than one event. Stratified into gender; $6.5 \%$ of the males $(1.6 \%>1$ event $)$, and $6.3 \%$ of the females $(1.0 \%>1$ event $)$, had experienced severe hypoglycaemia during 2011 (34).

Hospitalized with diabetic ketoacidosis

Diabetic ketoacidosis (DKA) is defined as hospitalized with $\mathrm{pH}<7.3$ or bicarbonate $<15 \mathrm{mmol} / 1$. In 2011 , $4.8 \%$ of the patients were hospitalized with DKA, $0.6 \%$ had more than one event. Stratified into gender; $4.7 \%$ of the males $(0.5 \%>1$ event $)$ and $5.1 \%(0.7 \%>$ 1 event) of the females were hospitalized with DKA (34).

\section{Nephropathy screening}

Nephropathy screening includes measurement of urinary albumin excretion rate in either $24 \mathrm{~h}$ or overnight 
urine collection or by urine albumin/creatinine ratio. Urine-albumin measurements are done at a local laboratory by standard sensitive immunological methods. In 2011 , urine samples were collected from $86 \%$ of the patients. $96 \%$ were screened accordingly to ISPAD consensus guidelines (16). Persistent microalbuminuria was found in $0.6 \%$ of the patients, $1.0 \%$ had albuminuria (23).

\section{Retinopathy screening}

The retinopathy screening includes fundus examination (fundoscopi) in mydriasis (after pupil dilation) performed by experienced local ophthalmologist. In $2011,41 \%$ of the patients had retinopathy screening. $68 \%$ were screened accordingly to ISPAD consensus guidelines (16). No one had laser treatment. $0.3 \%$ had non proliferative diabetes retinopathy (23).

\section{Intensified insulin treatment}

Intensified insulin treatment refers to either using insulin pump or four or more insulin injections per day. The insulin treatment has changed during the years. In $2001,9 \%$ of the youths in NCDR used insulin pump and $33 \%$ were on mix insulin. In $2011,59 \%$ used insu- lin pump, only $0.3 \%$ was on mixed insulin. Less than $5 \%$ use one to two daily insulin injections (23).

\section{Smoking}

A significant decline in the incidence of smoking among patients above 15 years was observed from $2001(18 \%)$ to $2005(5 \%)(p<0.001)(33)$. Since 2006 the incidence has been rather stable with $6 \%$ in 2010 and 2011 (23). The topic of how important it is to encourage young people to stop smoking or never start smoking has been discussed in NCDR annual meetings.

\section{ANNUAL MEETING IN NorWEGIAN Childhood Diabetes Registry}

Difference in outcome among treatment centres revealed by the Benchmarking centre report, provide a basis for discussion. Likewise has the screening for late complications and associated diseases according to international guidelines (16), improved following discussions at the annual NCDR meeting, leading to changes in screening assessments. This illustrates the value of a national quality circle in the NCDR.

\section{REFERENCES}

1. Soltesz G, Dahlquist GG. Global trends in childhood type 1 diabetes. Diabetes Atlas, 3rd Edn. 2012: 154-8.

2. Joner G, Sovik O. Increasing incidence of diabetes mellitus in Norwegian children 0-14 years of age 19731982. Diabetologia 1989; 32 (2): 79-83.

3. Aamodt G, Stene LC, Njolstad PR, Sovik O, Joner G. Spatiotemporal trends and age-period-cohort modeling of the incidence of type 1 diabetes among children aged $<15$ years in Norway 1973-1982 and 1989-2003. Diabetes Care 2007; 30 (4): 884-9.

4. Skrivarhaug T. Annual report 2009, The Norwegian Childhood Diabetes Registry, www.barnediabetes.no. 2010 .

5. Skrivarhaug T, Bangstad HJ, Stene LC, Sandvik L, Hanssen KF, Joner G. Long-term mortality in a nationwide cohort of childhood-onset type 1 diabetic patients in Norway. Diabetologia 2006; 49 (2): 298-305.

6. Patterson CC, Dahlquist G, Harjutsalo V, Joner G, Feltbower RG, Svensson J, et al. Early mortality in EURODIAB population-based cohorts of type 1 diabetes diagnosed in childhood since 1989. Diabetologia 2007; 50 (12): 2439-42.

7. Groop PH, Thomas MC, Moran JL, Waden J, Thorn LM, Makinen VP, et al. The presence and severity of chronic kidney disease predicts all-cause mortality in type 1 diabetes. Diabetes 2009; 58 (7): 1651-8.

8. Harjutsalo V, Forsblom C, Groop PH. Time trends in mortality in patients with type 1 diabetes: nationwide population based cohort study. BMJ 2011; 343: d5364.

9. The Diabetes Control and Complications Trial Research Group. The effect of intensive treatment of diabetes on the development and progression of long-term complications in insulin-dependent diabetes mellitus. $N$ Engl J Med 1993; 329: 977-86.

10. The Diabetes Control and Complications Trial Research Group. Effect of intensive diabetes treatment on the development and progression of long-term complications in adolescents with insulin-dependent diabetes mellitus. J Pediatr 1994; 125: 177-88.

11. Mohsin F, Craig ME, Cusumano J, Chan AK, Hing S, Lee JW, et al. Discordant trends in microvascular complications in adolescents with type 1 diabetes from 1990 to 2002. Diabetes Care 2005; 28 (8): 1974-80.

12. Nathan DM, Cleary PA, Backlund JY, Genuth SM, Lachin JM, Orchard TJ, et al. Intensive diabetes treatment and cardiovascular disease in patients with type 1 diabetes. $N$ Engl J Med 2005; 353 (25): 2643-53.

13. Dahl-Jorgensen K. Near-normoglycemia and late diabetic complications. The Oslo Study. Acta Endocrinol Suppl 1987; 284: 1-38.

14. The Epidemiology of Diabetes Interventions and Complications (EDICT) Study. Sustained effect of intensive treatment of type 1 diabetes mellitus on development and progression of diabetic nephropathy. JAMA 2003; 290: $2159-67$. 
15. Diabetes Research in Children Network Study Group. Comparison of fingerstick hemoglobin A1c levels assayed by DCA 2000 with the DCCT/EDICT central laboratory assay: results of a Diabetes Research in Children Network (DirecNet) Study. Pediatr Diabetes 2005; 6: 13-6.

16. Hanas R, Donaghue KC, Klingensmith G, Swift PG. ISPAD clinical practice consensus guidelines 2009 compendium. Introduction. Pediatr Diabetes 2009; 10 (Suppl 12): 1-2.

17. Patterson CC, Gyurus E, Rosenbauer J, Cinek O, Neu A, Schober E, et al. Trends in childhood type 1 diabetes incidence in Europe during 1989-2008: evidence of non-uniformity over time in rates of increase. Diabetologia 2012; 55 (8): 2142-7.

18. Skrivarhaug T, Stene LC, Strøm H, Drivvoll AK, Njølstad PR, Joner G. Increasing incidence of childhood onset type 1 diabetes in Norway. Diabetologia 2010; 53 (Suppl 1): 142.

19. The DIAMOND Project Group. Incidence and trends of childhood Type 1 diabetes worldwide 1990-1999. Diabet Med 2006; 23: 857-66.

20. Patterson CC, Dahlquist GG, Gyurus E, Green A, Soltesz G. Incidence trends for childhood type 1 diabetes in Europe during 1989-2003 and predicted new cases 2005-20: a multicentre prospective registration study. Lancet 2009; 373 (9680): 2027-33.

21. Berhan Y, Waernbaum I, Lind T, Mollsten A, Dahlquist G. Thirty years of prospective nationwide incidence of childhood type 1 diabetes: the accelerating increase by time tends to level off in Sweden. Diabetes 2011; 60 (2): 577-81.

22. Harjutsalo V, Sund R, Knip M, Groop PH. Changes over time in type 1 diabetes. Diabetologia 2012; 55 (Suppl 1): S105.

23. Skrivarhaug T. Annual report 2011, The Norwegian Childhood Diabetes Registry, www.barnediabetes.no. 2012.

24. Karvonen M, Pitkaniemi M, Pitkaniemi J, Kohtamaki K, Tajima N, Tuomilehto J. Sex difference in the incidence of insulin-dependent diabetes mellitus: an analysis of the recent epidemiological data. World Health Organization DIAMOND Project Group. Diabetes Metab Rev 1997; 13 (4): 275-91.

25. Tuomilehto J, Virtala E, Karvonen M, Lounamaa R, Pitkaniemi J, Reunanen A, et al. Increase in incidence of insulin-dependent diabetes mellitus among children in Finland. Int J Epidemiol 1995; 24 (5): 984-92.

26. Gardner SG, Bingley PJ, Sawtell PA, Weeks S, Gale EA. Rising incidence of insulin dependent diabetes in children aged under 5 years in the Oxford region: time trend analysis. The Bart's-Oxford Study Group. BMJ 1997; 315 (7110): 713-7.

27. Dahlquist G, Mustonen L. Analysis of 20 years of prospective registration of childhood onset diabetes time trends and birth cohort effects. Swedish Childhood Diabetes Study Group. Acta Paediatr 2000; 89 (10): 1231 7.

28. Harjutsalo V, Sjoberg L, Tuomilehto J. Time trends in the incidence of type 1 diabetes in Finnish children: a cohort study. Lancet 2008; 371 (9626): 1777-82.

29. Weets I, De Leeuw IH, Du Caju MV, Rooman R, Keymeulen B, Mathieu C, et al. The incidence of type 1 diabetes in the age group 0-39 years has not increased in Antwerp (Belgium) between 1989 and 2000: evidence for earlier disease manifestation. Diabetes Care 2002; 25 (5): 840-6.

30. Pundziute-Lycka A, Dahlquist G, Nystrom L, Arnqvist H, Bjork E, Blohme G, et al. The incidence of Type I diabetes has not increased but shifted to a younger age at diagnosis in the 0-34 years group in Sweden 19831998. Diabetologia 2002; 45 (6): 783-91.

31. Levy-Marchal C, Patterson CC, Green A. Geographical variation of presentation at diagnosis of type I diabetes in children: the EURODIAB study. Diabetologia 2001; 44 (Supp1 3): B75-B80.

32. Skrivarhaug T, Drivvoll AK, Kummernes SJ, Joner G. Diabetic ketoacidosis at onset in children and adolescents with type 1 diabetes in Norway - a nationwide population-based cohort study. Pediatr Diabetes 2012; 13 (Suppl 17): 49.

33. Margeirsdottir HD, Larsen JR, Kummernes SJ, Brunborg C, Dahl-Jorgensen K. The establishment of a new national network leads to quality improvement in childhood diabetes: implementation of the ISPAD Guidelines. Pediatr Diabetes 2010; 11 (2): 88-95.

34. Skrivarhaug T, Kummernes SJ, Drivvoll AK, Dahl-Jørgensen K. Severe hypoglycemia and diabetic ketoacidosis among children with type 1 diabetes in a population based, nationwide cohort. Pediatr Diabetes 2012; 13 (Suppl 17): 50. 